\title{
Local content requirements and the impact on the South African renewable energy sector: A survey-based analysis
}

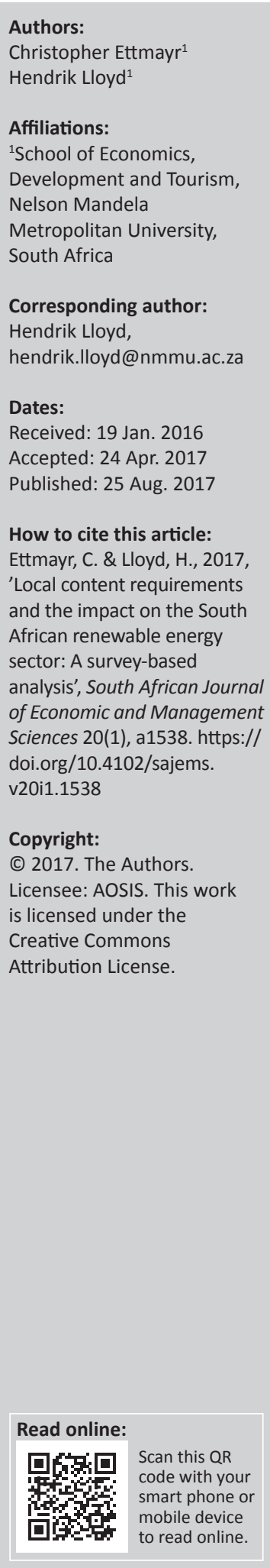

Background: Economies aim to grow over time, which usually implies the need for increased energy availability. Governments can use their procurement of energy to increase benefits in their economies via certain policy tools. One such tool is local content requirements (LCRs), where the purchase of goods prescribes that a certain value has to be sourced locally. The argument for this tool is that spending is localised and manufacturing, as well as job creation, can be stimulated because industry will need to establish in the host economy. However, this practice is distortionary in effect and does not create a fair playing ground for global trade. Furthermore, if the local content definition is weak, or open to manipulation, the goals of such a policy may not be achieved at all.

Aim: The objective of this study was to determine how LCRs would ultimately impact on the overall procurement programme.

Setting: This study took place as South Africa commenced with large scale development of the renewable energy sector. This was largely achieved via the State run Renewable Energy Independent Power Producer Procurement Programme (REIPPPP).

Method: This study utilised opinion-based surveys to look into the LCRs of South Africa's REIPPPP and measure the impact of this policy on the renewable energy sector in general. The mixed method approach was utilised to analyse qualitative and quantitative data and this was then triangulated with an international peer group to arrive at certain conclusions. The Delphi Technique was then employed to achieve population consensus on the findings.

Results and conclusion: It was found that, in order to implement a policy such as local content without any negative welfare effects, the host economy had to show certain pre-existing conditions. Because South Africa does not hold all supportive pre-conditions, the impact and effect of LCRs have not been optimal, and it has not been found to be a sustainable mechanism to continue using indefinitely. The pricing of renewable energy was also found to be higher due to local content and such pricing is passed on to the energy consumer. The welfare created for South Africa, which should be in a trade-off for the creation of jobs and manufacturing, is therefore diminished and coupled with unsustainability and potential manipulation of the system, the country does not seem to be benefitting as it should be from this specific application of a local content policy.

\section{Introduction}

Countries around the world are aiming to grow their economies, implying that the demand for energy from electricity sectors will increase. Because of the increasing development, there are larger and more demanding power users; if power is not readily available it could place serious constraints on the economy. To add further complexity to this matter is the notion of developing a green economy that involves, on the one hand, growing the economy and, on the other hand, reducing environmental impact and improving human social development. This has been a trend in developed countries, now evident in developing nations too.

The United Nations Environment Programme (UNEP) is in support of this notion and defines the green economy as 'one that results in improved human well-being and social equity, whilst significantly reducing environmental risks and ecological scarcities' (UNEP 2011:2). This concept provides a dichotomy for governments, whereby the demand for energy is rising, but generation costs need to be low enough to remain attractive for inward investments. In addition, the increased provision of energy must not negatively impact the environment or human well-being. Within the context of the green economy, governments are using green industrial policies to meet certain objectives, such as increased energy generation, higher employment and faster economic growth. This ultimately increases the associated energy costs (Kuntze \& Moerenhout 2013:vi). 


\section{Local content requirements and the impact on economies \\ Local content in the South African renewable energy sector}

South Africa has seen a similar trend as the scenario described above, whereby the economy has been growing and placing increased pressure on the electricity supply. To increase electrical supply in the country, renewable energy has been recognised as an essential part of a mix of energy carriers that offer a positive impact on environmental and human wellbeing (as compared to fossil fuel). The South African government announced that it was to procure renewable energy from independent power producers (IPPs), according to the requirements of the Integrated Resources Plan (IRP) 2010 - promulgated under the Electricity Regulation Act, 2006 (Act No. 4 of 2006). The IRP 2010 document committed government to having $17.8 \mathrm{GW}$ of renewable energy installed by 2030 (Department of Energy 2011a:6).

In an effort to meet the targets presented in the IRP 2010 document, the Minister of Energy released a determination in 2011, stating that a total of 3725 MW would be procured by 2016 through one or more tendering processes. The energy to be procured from renewable sources would include wind, concentrated solar power (CSP), solar photovoltaic (PV), biogas, biomass, landfill gas, small hydro and small (under 5 MW) projects (Department of Energy 2011b:118-119). Then, in December 2012 an announcement of an additional 3200 MW of renewable energy to be purchased through the Renewable Energy Independent Power Producer Procurement Programme (REIPPPP) was made by the DOE, pushing the programme's expected completion date from 2016 to 2020 [Department of Trade and Industry (DTI) 2015:xi]. The DOE made further allocations of $1000 \mathrm{MW}$ in round 4 of the REIPPPP, plus another $200 \mathrm{MW}$ was allocated to CSP projects. In addition, a request for further proposals was put forward by the Minister of Energy for $1800 \mathrm{MW}$, which would be allocated to bidders previously unsuccessful but able to revise their tenders and re-submit. The minister went further to announce that an additional 6300 MW was applied for through the National Energy Regulator of South Africa (NERSA), in accordance with provisions in the IRP 2010-2030 (DOE 2014b, 2015; Engineering News Article 2014a).

The REIPPPP also included a portion of projects termed 'small scale' that was designed to include those between 1 MW and 5 MW. During the first small scale window application period, 102 projects were submitted with the potential for generating $450 \mathrm{MW}$. However, only 78 projects were successful, totalling $345 \mathrm{MW}$ (Engineering News Article 2014b). The implications of such a large tender were significant to countries such as South Africa. At the time of writing this paper, four rounds of the REIPPPP had been concluded: 92 projects were approved with a combined nameplate capacity of 5243 MW. This resulted in an investment value of R193 billion (bn) (Engineering News Article 2015). The DOE noted that of this investment value,
R53.4bn was from foreign sources that increased South Africa's inward foreign direct investment (FDI) in 2015 by just more than double with the other total FDI for the same period being R22.6bn (DOE 2016:27).

The DTI created an industrial policy that complies with the South African laws but sets certain prerequisites for the use of policy tools such as local content. The DOE identified key features of the REIPPPP that they felt would be catalytic for achieving economic development objectives, whilst aligning with the DTI policies. These are as follows:

- develop projects that lead to new opportunities for local communities

- create job opportunities in certain technologies and especially in construction

- opportunity for procurement to be structured by government, emphasising certain economic development objectives

- formation of new companies combining emerging black enterprises with experienced, well-resourced companies (in terms of equity share and project management)

- promotion of Broad Based Black Economic Empowerment (BBBEE) potential via subcontracting and procurement to include large, medium and small enterprises, bringing benefit to target groups of people

- involvement of black equity and management skills through the extended time-frame IPPs would operate in (DOE 2011:92-93).

Based on the objectives above, the DOE developed a table of socio-economic outputs that had to be met, or exceeded, in order for tenderers to become a 'preferred bidder' in the REIPPPP. The tender adjudication was based on the 70-30 principle where $70 \%$ would be evaluated on price and $30 \%$ would make up the socio-economic criteria. From the latter, there was a further breakdown (see Table 1 in which certain points were obtainable based on the objectives provided in the bulleted points above).

Each renewable energy project required a minimum of $40 \%$ participation by a South African entity, a minimum ownership by black South Africans of $12 \%$ (with the target set at $20 \%$ ) and a minimum ownership of a local community of $2.5 \%$, where the community lived within a $50-\mathrm{km}$ radius of the project (Baker \& Wlokas 2014:10). Local content requirements (LCRs) featured in the economic development criteria and

TABLE 1: Socio-economic criteria for the renewable energy independent power producer procurement programme.

\begin{tabular}{lcc}
\hline Economic development element & Weight & Effective \% in scoring approach \\
\hline Job creation & 25 & 7.5 \\
Local content & 25 & 7.5 \\
Ownership & 15 & 4.5 \\
Management control & 5 & 1.5 \\
Preferential procurement & 10 & 3 \\
Enterprise development & 5 & 1.5 \\
Socio-economic development & 15 & 4.5 \\
\hline Total & $\mathbf{1 0 0}$ & $\mathbf{3 0 . 0}$
\end{tabular}

Source: Adapted from Department of Energy of the Republic of South Africa (DOE), 2011b, Tender No: DOE/001/2011/2012, Request for Qualification and Proposals for New Generation Capacity Under the IPP Procurement Programme. 
the government used this specific tool in an attempt to commit to industrial development. The National Development Plan (NDP) and the New Growth Plan (NGP) utilise local content as a policy tool to stimulate development and to try and maximise benefits for the immediate economy; this programme from the DOE was aimed at doing the same (DOE 2011). The term local content has been defined by the South African Bureau of Standards (SABS) as:

that portion of goods, works and services that have been generated and produced in South Africa. Companies that import raw material and convert this raw material in South Africa also contribute to local content to the extent that the South African value-add processes and additional inputs count as local content. (GIZ 2013a:27)

The calculation of local content is illustrated in Box 1 .

In Table 2, the levels required from the REIPPPP per technology are summarised. It is important to note that the levels generally increase with each round of bid submissions.

The difference between the threshold levels (above) and the targetlevels were defined in the REIPPPPtender documentation. Bidders had to achieve the minimum requirement threshold levels to be compliant; they were, however, encouraged to attempt to reach target levels as the intention of the DOE (in alignment with the DTI industrial policies) was to maximise local benefits. The percentages were evaluated on a sliding scale where no points were allocated to bidders achieving threshold level. As higher percentages were achieved, more points were awarded until the maximum points were gained by those bidders able to reach target in their submission.

\section{Local content impact on investment}

Certain key drivers are needed to create a climate conducive to encouraging investment in the renewable energy sector

BOX 1: Local content formula.

$$
\begin{aligned}
& \text { LC }=(1-\mathrm{x} / \mathrm{y}) * 100 \\
& \begin{array}{ll}
\text { where: } & \mathrm{x} \text { is the imported content in Rands and } \\
& \mathrm{y} \text { is the bid price in Rands excluding value-added tax (VAT). }
\end{array}
\end{aligned}
$$

Source: Adapted from SABS, 2011, 'SATS 1286: 2011 Edition 1: Local goods, services and works - Measurement and verification of local content', Pretoria, p. 4, viewed 28 May 2014 from http://www.dti.gov.za/industrial_development/docs/ip/technical.pdf and although LCRs create a drawcard for manufacturers to consider establishing in a new economy, there are additional drivers to support this move. Abrahams (2012) argues that the drivers necessary for establishing a renewable energy manufacturing hub in South Africa would include:

- a sustainable renewable energy market with growth prospects

- a strong supply-side support that would include established supplier relationships and manufacturer capabilities

- the presence of skilled labour

- physical location and infrastructure availability

- research and development (R\&D) presence that is accessible

- the existence of incentives for manufacturers

- a supportive government. (p. iv)

The first key driver to be tested in this research would be the market strength and potential growth of the sector. South Africa has committed to a renewable energy programme that holds predetermined levels of energy to be purchased per technology. Therefore, the market for IPPs and manufacturers has been established, and demand has been shown to be present, with potential for future expansion. Because a strong supplier support was listed as a key driver, the existence of local manufacturers and suppliers of renewable energy technologies, components and ancillary items would be conducive to investment attraction.

Domestic skilled labour is required for sector support, as there is currently criticism about the large influx of foreign labour used to erect and develop renewable energy projects in South Africa. IPPs have, however, indicated through media releases that the required skilled labour is not present in the country, and this represents challenges to IPPs wanting to maximise their local content spend. There are studies, at the time of writing, which are testing the market in terms of being able to supply suitably qualified labour for work in renewable energy by original equipment manufacturers (OEMs).

Physical location of renewable energy projects is also important since IPPs need to locate in areas with optimal

\begin{tabular}{|c|c|c|c|c|c|c|c|c|}
\hline \multirow[t]{3}{*}{ Technology } & \multicolumn{8}{|c|}{ REIPPPP local content requirements } \\
\hline & \multicolumn{2}{|c|}{ Round 1} & \multicolumn{2}{|c|}{ Round 2} & \multicolumn{2}{|c|}{ Round 3} & \multicolumn{2}{|c|}{ Round 4} \\
\hline & Threshold (\%) & Target $(\%)$ & Threshold (\%) & Target $(\%)$ & Threshold (\%) & Target $(\%)$ & Threshold (\%) & Target (\%) \\
\hline Wind & 25 & 45 & 25 & 60 & 40 & 65 & 40 & 65 \\
\hline Solar PV & 35 & 50 & 35 & 60 & 45 & 65 & 45 & 65 \\
\hline $\begin{array}{l}\text { Solar CSP without } \\
\text { storage }\end{array}$ & 35 & 50 & 35 & 60 & 45 & 65 & 45 & 65 \\
\hline Solar CSP with storage & 25 & 45 & 25 & 60 & 40 & 65 & 40 & 65 \\
\hline Biomass & 25 & 45 & 25 & 60 & 40 & 65 & 40 & 65 \\
\hline Biogas & 25 & 45 & 25 & 60 & 40 & 65 & 40 & 65 \\
\hline Landfill gas & 25 & 45 & 25 & 60 & 40 & 65 & 40 & 65 \\
\hline Small hydro & 25 & 45 & 25 & 60 & 40 & 65 & 40 & 65 \\
\hline
\end{tabular}
renewable energy resources, and manufacturers need to be

TABLE 2: REIPPPP local content requirement percentage levels.

REIPPPP, renewable energy independent power producer procurement programme; PV, photovoltaic; CSP, concentrated solar power.

Source: Department of Energy of the Republic of South Africa (DOE), 2011b, Tender No: DOE/O01/2011/2012, Request for Qualification and Proposals for New Generation Capacity Under the IPP Procurement Programme; Department of Energy of the Republic of South Africa (DOE), 2014a, Tender No: DOE/O03/13/14, Request for Qualification and Proposals for New Generation Capacity Under the REIPP Procurement Programme, Volume 5: Economic Development Requirements, Updated for the Fourth Bid Submission Date, South African Department of Energy, Pretoria. 
close to their customers so as to minimise logistical costs (these can be quite high for the larger and abnormal loads that characterise some technologies, e.g. large wind turbine blades and towers). Electrical transmission infrastructure is equally important as this is needed to ensure grid connectivity and the ability of the system to evacuate and distribute the power generated on-site.

Manufacturing also relies largely on supportive infrastructure being present. The ability of South Africa's logistical and electrical infrastructure to support local manufacturers of renewable energy technologies and components was tested during the survey process. The fact of whether local suppliers are able to produce such manufactured goods at the right quality levels and price was also questioned in the survey.

$R \& D$ is important to IPPs and manufacturers alike as it can lower costs and improve efficiencies. However, due to technologies already tested and proven internationally, the IPPs in South Africa are generally installing and developing projects with very little $R \& D$ investment. $R \& D$ is more relevant to the manufacturing of renewable energy components and it is usually found that the country of origin of a particular technology will tend to keep this intellectual property and R\&D local, whilst only allowing some manufacturing of the most basic subcomponents to be outsourced.

The existence of incentives for IPPs is important and South Africa currently uses such for investment attraction. However, with the IPPs looking to tender in the REIPPPP, the tender itself could be viewed as an incentive since it is a guaranteed take-off for energy to be produced over a 20-year period.

Lastly, a supportive government is important for manufacturers and IPPs alike. Government can indicate support via the procurement of renewable energy and can set targets and goals that show future demand continuing for the supply of such energy. National projects via South Africa's National State utility, Eskom, as well as through the DOE - previously done in South Africa - send out positive signals of support.

Ultimately, throughout the conflicting debate on the impact of LCRs it is acknowledged that local content will have an impact on investment attraction, although this has not been determined in the case of the South African renewable energy sector. An increase in investment, especially from FDI, does have a positive association with economic growth and, therefore, benefit to the local economy. From literature and research based on econometric techniques and case studies, Veloso (2001) refers to the impact of FDI where all indicators point to the fact that it contributes to economic growth and reinforces the learning processes of industrialising nations. There was also evidence that there was a spill-over effect from FDI, providing an increase in the economic growth rate (Veloso 2001:21-23). This study, therefore, looks at the relationship between LCR levels and their impact on investment attraction; it is assumed that increased investment through foreign sources will naturally have a positive effect on the local economy.

\section{Specific aspects regarding setting of local content requirements}

Setting LCRs is complex and multi-faceted since, on the one hand, LCRs can add value to locally-produced goods and can stimulate R\&D and innovation, but on the other hand LCRs can distort international trade and affect the efficient allocation of resources. It has been noted that '(g)lobally, LCR for renewable technologies in different forms have been used in rare instances and mainly in developing countries' (EBRD Blog 2012:1).

One of the main justifications put forward by developing countries in defence of LCRs is that they are relevant when the type of industry is completely new to their economy. They therefore use LCRs in order to stimulate and develop an infant industry, which they intend to establish into a mainstream manufacturer that can compete globally. This argument can be justified, but countries do not always reduce or remove LCRs after a period, in which case this can become a trade barrier. Therefore, countries are not always in a position to be able to select the highest quality of goods at a competitive price because LCRs have a direct influence on the procurement of these goods or services. A new phrase has been coined in this regard - 'clean energy trade war' - where countries use LCRs to justify the blocking of free trade in the name of transitioning to more environmentally-friendly means of developing energy (Kuntze \& Moerenhout 2013:vi).

\section{When to use local content policy}

Local content can achieve many successes in a host economy; however, there are certain pre-conditions that need to be present before implementing such a policy. Kuntze and Moerenhout (2013:1) identified these key conditions. Firstly, there would have to be a 'stable and sizeable market' for which financial support should be available. This was seen as crucial, to avoid the crowding out of investment. In addition, the LCRs should not be set too high or be too restrictive and they should have a learning aspect tied into them in order to ensure skills transfer, thereby increasing efficiencies over the long term (Kuntze \& Moerenhout 2013:1). The basic preconditions for effectively implementing LCRs in a particular economy are summarised in Figure 1.

\begin{tabular}{|lll|}
\hline \multicolumn{2}{|l|}{ Potential investment loss } & \multicolumn{1}{c|}{ Potential investment benefit } \\
$\stackrel{\text { Small }}{\stackrel{\text { Market size and stability }}{ }}$ \\
Too restrictive & Restrictiveness of LCR & Large \\
Non-existent & Cooperation and subsidies & Proper \\
Low & Learning-by-doing and technical knowledge & High \\
\hline
\end{tabular}

LCRS, local content requirements.

Source: Adapted from Kuntze, J. \& Moerenhout, T., 2013, Local content requirements and the renewable energy industry - A good match, International Centre for Trade and Sustainable Development (ICTSD), p. 11, Geneva, Switzerland.

FIGURE 1: Basic conditions needed for effective local content requirements in renewable energy. 


\section{Local content policy advantages}

Kuntze and Moerenhout (2013:6-9) found that LCRs increased the demand for certain products, which in turn increased the demand for staff, brought in new technologies and - because more manufacturing was taking place - the tax base for government increased. Wu and Salzman (2014:422-423) similarly concluded that local content increased the demand for domestically-produced goods, leading to higher levels of employment. Lewis (2013:4) found an interesting spin-off from increased local manufacturing as global competition increased in response to more market entrants, product costs were driven down and technological innovation increased.

\section{Local content policy disadvantages}

Local content requirements can bring about negative consequences such as inflationary pressure on prices, incentivising business to misallocate resources, and impacting on trade relations by using a form of protectionist measure. It was also found that because of local content, companies may employ fewer staff due to the increased expenses caused by the policy and this also restricts the transfer of technologies (Kuntze \& Moerenhout 2013:6-9).

The GIZ (2013b:29) found that local content limited the level of natural competition and Nowicki (1997:363) found that it disrupted the production and planning choices of manufacturers, which led to higher prices. In the specific case of South Africa's renewable energy industry, local content was found to allegedly increase the cost of renewable energy equipment, which may encourage a strategy of reducing the amount of staff allocated to a project and less energy output would be available for the same investment amount. Brazil noted that when implementing LCRs in their wind sector, manufacturers only shifted the low and medium content production to their country, whilst the high technology components of their manufacturing process remained in the country of origin (Rennkamp \& Westin 2013).

When analysing the automotive sector which has used LCRs extensively, there are numerous examples of the impact of this tool. Barnes and Black (2013:14-15) found that companies focused mainly on assembly, and not manufacturing, to reach the required levels of local content. Second tier suppliers also used mainly imported goods over locally-manufactured goods and aspects such as advanced work and tooling, as well as technology investment, still took place outside of South Africa (Barnes \& Black 2013:14-15). The Philippines found inefficiencies in their performance standards which included LCRs, embargoes on imported vehicles, and tariffs on import and export requirements. It was estimated that - due to the protectionist policy - the cost to the consumer was approximately $40 \%$ of the vehicle price. This effect was mostly attributed to the tariff and if LCRs and the export requirements were removed, the result would change by approximately 10\% (Veloso 2001:37).
LCRs have been listed as being responsible for both successes and failures of certain projects in the chemicals and computer sectors, depending on the specifics of each project and technology. It was estimated that - because of LCRs - in Brazil, computers cost up to $200 \%$ to $300 \%$ more than if sourced outside of the country and this has slowed the use of this technology and reduced the pace of upgrading to new systems (Veloso 2001:38).

Negative criticism found by Eberhard, Kolker and Leigland (2014:28-29) of LCRs in the REIPPPP were that:

- LCRs were expressed in value terms but the worth of each job in a particular value chain is not measured; LCRs could therefore be refined to focus rather on maximising jobs of high value than simply creating as many positions as possible.

- If there is no capacity-building of the local market to supply developers there is an increase in inefficiencies and little skills transfer from the programme, increasing the costs for the foreign operators and developers.

- LCRs are oblivious to market conditions and currently there is an oversupply of renewable technologies, which makes local manufacturing profits very difficult to achieve. Well established and mature manufacturers need to observe a very strong and sustainable market in order to justify moving into a new region (Eberhard et al. 2014:28-29).

\section{The Analytical framework (Research methodology)}

Due to the scarcity of information on LCR impact in the renewable energy sector the mixed method approach, which combines qualitative and quantitative methodologies, was employed. This method lends itself well to this type of research problem as data can be gathered and analysed in a quantitative manner whilst simultaneously delving deeper into specific qualitative aspects. In areas with limited secondary research, the qualitative methodology can be brought in to bolster the research and allow exploration of the research problem. The mixed method approach results in more meaningful and reflective knowledge generated from the study. The surveys developed for this study used both open- and closed-ended questions, with the latter employing a Likert scale to record responses.

The survey design used the Delphi Technique as this method of iteration would allow for respondents to answer the first survey and then - once presented with the total overall results - they could either agree or answer differently in subsequent rounds of surveys being administered. This allowed for consensus to be gained from a broad array of respondents with differing views on the subject. The Delphi Technique was also found to be very useful in exploring this type of research topic where limited information existed on the impact of LCRs. There were essentially two identified groups of survey respondents - the first was the local IPP and Engineering, Procurement and Construction (EPC) 
companies who were directly involved in the REIPPPP projects from rounds 1 to 4 and who therefore had direct exposure to working with a policy tool such as LCRs. Their practical experience and challenges in working with this tool was questioned via the survey process. The second group was comprised of an international group of renewable energy experts. This group was used to test and compare the responses to the local respondents. The methodology of triangulating the data was employed, whereby the literature was compared against the data collected from the local survey respondents and then compared against the international respondents. This ultimately resulted in a wellrounded response to the research problem and provided increased robustness and confidence in the conclusions that were drawn.

A pilot survey was administered on a select group of respondents whose responses were captured with the total group. This provided face validity of the survey questions and allowed for minor corrections to be made before administering the full survey. The study population is defined as all REIPPPP-successful bidders and their EPC companies. During the first four rounds of the REIPPPP, 79 projects achieved preferred bidder status and this group forms the total population size (N pop). A total number of 43 IPPs developed these 79 projects and some IPPs held shares in more than one project (entering into joint venture partnerships with each other in certain instances). The number of EPC companies (with some IPPs also performing EPC functions) from the four rounds of the REIPPPP was 23 in total. Therefore the total population sample group was 66 (n sample). A total of $48 \%$ (56 of the 115 respondents) of the identified IPPs answered the survey, 43\% (11 of the 28 respondents) of the identified EPCs provided answers and $39 \%$ (5 of the 13 respondents) of the international group responded. The data that was collected did not go through any reliability testing as there was no pre-existing data for the results to be tested against. Because of the employment of information triangulation, it was determined that this technique would be sufficient to produce reliable data for analysis and interpretation.

\section{Ethical consideration}

Ethics clearance was obtained via the Faculty Research, Technology and Innovation Committee.

\section{Data analysis and findings}

Based on the data that was analysed from the IPP/EPC surveys and using the Delphi Technique, the results are discussed below. This includes triangulating the findings with the results from the international group against the IPP / EPC data, and from the theory obtained relating to LCRs impact. Therefore, the theory informed the development of the surveys, the results were tested locally and abroad, and the Delphi Technique allowed for a convergence of thinking towards one unified response to the impact of LCRs on the renewable energy sector in South Africa. Key determinants that may be impacted by LCRs were identified for testing and they were broadly categorised into six main sections, described below under each category heading.

\section{Data analysis}

The data obtained from the survey underwent the first statistical test - the confidence interval. Additional tests performed were the Pearson's Chi-square, cross-tabulation and Cramer's V. The Pearson's Chi-square test was found to be invalid for this study because the population was too small; however, cross-tabulation was employed to highlight the magnitude of the difference between answers from the local survey and the international findings and furthermore, the Cramer's V test was used to measure the practical significance of each particular finding.

\section{Findings}

\section{The renewable energy market}

It was found by $75.8 \%$ of respondents from the IPP/EPC survey that the South African REIPPPP created a strong local demand for renewable energy projects, which encouraged investment in the sector. It was also observed that the first three rounds of the REIPPPP resulted in R120bn of total project costs locating in South Africa (SAPVIA 2014) and when triangulated with the findings from the international survey where $80 \%$ agreed that the REIPPPP created sufficient market demand, this statement was accepted. However, the South African renewable energy market was not rated as particularly stable with the confidence interval levels being below the 0.6 cut-off limit and the Fisher's Exact test value of 0.057. Predicted future growth prospects were not rated very positively and the statement of South Africa's market being stable was rejected because the confidence interval's upper and lower limits were below 0.6 and the Cramer's V of 0.051 showed small significance. Stability and predicted future growth were issues regarded as important key determinants and from the international survey where $60 \%$ of respondents agreed with the need for long term future growth) and therefore South Africa should look at improving this aspect.

The market was perceived to be relatively open to free trade with $54.5 \%$ of respondents from the IPP / EPC survey agreeing with this statement. A total of $60.6 \%$ of respondents from the IPP/EPC survey felt that the market was free from manipulation, and although it is believed that the answers given were only marginally positive in suggesting a lack of manipulation, the statistical tests did not allow for the acceptance of the hypotheses. Therefore, there may be some inclination to avoid admitting manipulation in the tender process as the IPPs and EPCs would be the same entities submitting false claims on local content in the REIPPPP process and would be liable for a fine.

In terms of access to finance and rates charged, it was found that $68.2 \%$ of respondents from the IPP/EPC survey felt that the cost of South African finance is higher than that from international sources and $78.8 \%$ of respondents from the 
same survey felt that the finance available is very difficult to access. The Cramer's V value of 0.115 places a medium significance on this finding so attention must be paid to improving access to finance. A matter that compounds the problem of finance for projects is exposure to exchange rate fluctuations (where $90.9 \%$ of respondents from the IPP/EPC survey felt that exchange rate exposure increases project risk), which increases project risk. Stabilising the South African rand is difficult to achieve but perhaps future projects could find a way to protect themselves from this market exposure as it was of significant concern to the IPPs and EPCs. The South African banking sector did however achieve a significant share in projects with the DOE (2016:27) report noting that after bid windows 1, 2, 3, 3.5, 4 and 1S2, a total of R194.1bn had been committed to the REIPPPP of which R53.4bn was raised from foreign sources. It was however believed that with more innovative mechanisms, local banks should be able to gain access to increase financing whilst decreasing risk exposure. The recent trend of IPPs financing themselves is providing a difficult platform for banks to compete against, but there may be ways in which to counter this and ensure that local financial institutions gain benefit from the REIPPPP.

Therefore, from a government perspective, South Africa could look at announcing clear long term plans regarding how it aims to procure renewable energy from the market in order to signal long term commitment to the sector something investors wish to see. Furthermore, government must be consistent in its procurement process and must adhere to the timelines announced as this creates market stability, improving the investment climate further. From a banking perspective, more innovative, accessible and low cost financing mechanisms need to be offered to the renewable energy market.

\section{Restrictiveness of local content requirements}

LCRs set in an economy that does not have existing preconditions conducive to accommodating such a policy tool have been found to result in a negative welfare effect, as experienced in the Indian automotive sector or Brazil's information technology sector. Similarly, LCRs that are too restrictive will cause a negative impact on investment. This section of the survey measured the impact of LCRs on investment, their restrictiveness, and their capacity to impact manufacturing and create jobs.

The local IPPs and EPCs found that South Africa's renewable energy LCRs resulted in investment, but this was a perception suggested by only $53 \%$ of respondents. This finding was triangulated with the theory as well as the international survey finding where $80 \%$ of respondents were of the opinion that LCRs encourage investment into the sector. The Fisher's Exact test value of 0.246 allowed for this statement to be accepted even with the low response rate from the IPP/EPC survey. Therefore, although LCRs would naturally result in increased investment in a host economy, it is because of the effects of a mandatory requirement and not because it is a sustainable market opportunity that is being exploited. The IPPs and EPCs did not believe LCRs in the country were set too high and so - although they may serve as a deterrent to investment - it was not seen as prohibitive to entering the South African market. In a qualitative survey response on the effect of LCRs on the project price, the opinion was that the average price increase attributable to the project from LCRs was $9.89 \%$.

A total of $80 \%$ of the international respondents were of the opinion that LCRs would increase manufacturing in South Africa but in terms of perceiving sustainability, the response rate decreased to $60 \%$, although still remaining positive. The confidence interval limits were $0.48-0.58$ that were not higher than the 0.6 cut-off, and therefore LCRs were not seen to create sustainable manufacturing in South Africa. Furthermore, the Cramer's V of 0.763 showed a large practical significance meaning that this matter should receive priority attention from the South African government. If LCRs create the incentive for manufacturing to establish and if this is the only reason that manufacturing locates in an economy, it is likely to move if the LCR was removed, or if the procurement programme ceased to exist. Also, if competing economies offer higher LCRs and more attractive markets it may result in a move for manufacturers. Therefore, LCRs will create manufacturing and investment, but this effect may only last as long as the content requirement is in place. To add to this sentiment, it was found by $34.8 \%$ of respondents from the IPP/EPC survey that they did not believe South Africa would be globally competitive in renewable energy manufacturing, sending out a signal that perhaps the focus on manufacturers alone should change to be more inclusive of a broader value chain perspective.

The IPP and EPC entities did not believe that removing LCRs would increase investment (with only 30.3\% agreeing). Also, the removal of LCRs - in the opinion of both the local $(100 \%$ agreeing) and international respondents (80\% agreeing) would not result in increased employment levels. Therefore, although it was felt that LCRs did not provide sustainable jobs or manufacturing, removing them completely would impact negatively on jobs and investment in the host economy. The removal of LCRs would allow IPPs to lower their pricing and thus their tariffs. However, with removing LCRs, a potential risk does arise whereby jobs may be lost and there would be a lack of a compulsory environment that dictates local investment has to take place. It was found from $71.2 \%$ of the IPP /EPC respondents that LCRs increase the price of the energy supplied and that this is carried by the taxpayer and energy user in South Africa. Another factor adding to project costs is the fact that by insisting on LCRs, project risk increases, which raises price and this is passed onto the consumer once again. Therefore, removing the LCRs would reduce project risk, which would further allow pricing of the energy to decrease as agreed by $66.7 \%$ of the IPP/EPC respondents.

Another challenge LCRs pose is the difficulty in sourcing local suppliers and - once sourced - their goods are often more expensive than a comparative imported good as 
agreed to by $72.7 \%$ of IPP/EPC respondents. It was found by $63.6 \%$ of IPP / EPC respondents that there are insufficient numbers of local suppliers in the industry. Furthermore, there was an almost neutral response to the question about local content values not necessarily being completely accurate which once again would point to the potential manipulation of local content figures being placed in tender bids.

To summarise, according to the survey outcomes, LCRs do increase local investment levels, manufacturing and jobs. However, the benefits created are not sustainable, and they increase project risks and costs, which end users and taxpayers ultimately pay for. There are benefits created by LCRs, but the manipulation of the system and its definition have been observed, which means that this policy tool is not able to maximise its intended purposes.

\section{Physical location and infrastructure}

South Africa is a suitable location for the establishment of renewable energy projects in terms of the availability of resources, for example, wind and solar radiation. This was the consensus of $93.9 \%$ of the IPP/EPC respondents and $100 \%$ of the international respondents.

In terms of transport, South African road, sea and air infrastructure enables investment and allows for projects to establish easily. The rail system is not used extensively, but this may be a practical response as rail is only present in certain geographic areas, whilst renewable energy projects can be located in very remote areas and in difficult terrain (it would be impractical to expect rail to service these projects). Furthermore, rail can only accommodate certain dimensions of goods and when considering abnormal loads, it may be unable to assist in their transportation, no matter how efficient. Rail infrastructure did not score very well in the survey process from the IPP/EPC respondents with $19.7 \%$ agreeing that rail allows for easy establishment of renewable projects. Therefore, rail should not be focused on for development or support of the renewable energy generation projects, as it will not necessarily lead to increased investment attraction, even if it becomes more efficient and economical.

Although South Africa's general infrastructure was rated well, the existing electrical infrastructure and its availability for connecting renewable energy projects scored poorly. A total of $47 \%$ of respondents from the IPP/EPC survey agreed that the electrical infrastructure attracts IPPs to establish their projects in the country. This is an area the IPP and EPC entities felt was actively discouraging investment in the sector and should be prioritised in terms of the country's infrastructure upgrades. There are currently renewable energy projects in existence that are unable to connect to the grid and sell their energy, and this has a direct impact on an IPP's profitability. Further improvements to electrical infrastructure as well as connectivity to the grid must be established.

\section{Government cooperation and subsidies}

It was agreed that government has a significant role to play in stimulating investment in the renewable energy sector with $68.2 \%$ of the IPP/EPC respondents and $80 \%$ of international respondents believing that government could stimulate this sector via certain programmes. The confidence interval range of $0.63-0.72$ allowed for this statement to be accepted. There was, however, a neutral response to the question on current government support encouraging investment, with a 50/50 split in responses. This may point to the need for further government assistance and when triangulating this response to the international survey it became apparent from $60 \%$ of respondents that - from an international perspective - it was felt that government incentives were needed to support the industry.

On the question of government involvement in the development of a renewable energy manufacturing cluster, there was overwhelming support from all respondents (77.3\% IPP/EPC and 80\% international survey respondents), in favour of government assistance. It was felt by $72.7 \%$ of IPP/EPC respondents that government support for localising technology suppliers and increasing technology capacity was lacking and that more could be done in this respect. The governance of the sector and cooperation from the South African government was noted as positive (60.6\% of the IPP/ EPC respondents agreeing), although not at a very high level. The policy support and a clear long term vision were perceived to be lacking as only $74.2 \%$ of respondents agreed or were neutral on this question. Therefore, a clear long term plan with the roll-out of a cluster approach may turn this result around and create a more enabling environment to support investment in the sector.

The question about a bidding tender system (which South Africa adopted) versus a set feed-in tariff was probed during the study, together with a query about which mechanism might be better. There are instances where one would be preferable, but in general 53\% of the IPP/EPC respondents believed that a feed-in tariff would have resulted in higher investment in the sector. The certainty that a feed-in tariff offers could therefore be noted as removing some uncertainty and investment in renewable energy projects would only increase marginally. The level of competition in the market at the moment is very high and so projects are only locating in areas with optimal resource availability and ease of connection to the electrical grid. Therefore, if the government and specific municipalities were to encourage investment in particular areas, the merits of using a feed-in tariff should be investigated more closely. This is also stated because of the findings from the international survey where $80 \%$ of respondents felt that a feed-in tariff may bring about higher investment levels.

\section{Learning-by-doing and technical knowledge}

It would appear that South Africa possesses some technical skills to support investment in the renewable energy sector, but not at a level sufficient to support it effectively (with 
$59.1 \%$ of IPP / EPC respondents agreeing to this; however the confidence interval did not allow the statement to be accepted). The accessibility of readily available skilled persons to support localisation is difficult to obtain, and although there is capability in EPC skills and O\&M functions, the number of persons able to offer their services to the market is limited.

In terms of manufacturers establishing in the economy, it was found that there is difficulty in locating in South Africa because of the low level of technology intensity in the market (making it hard to source skilled persons). From the existing skilled persons available only $53 \%$ of respondents felt that their services were competitively priced. This leads to the conclusion that the demand is high, but the resource is scarce; therefore price could have the tendency to be above average due to scarcity.

In terms of the capability of South Africa to skill people in this industry, it would be important that they are educated to a relevant level in order to be able to adapt quickly with minimal additional training. However, the IPP/EPC respondents were neutral in their response to the question about the level of education in South Africa being conducive to supporting the renewable energy sector and the confidence interval range $0.45-0.54$ did not allow for this finding to be accepted. Another negative factor is that the country's availability of R\&D for the renewable energy level would not encourage investment in the sector with only $10.6 \%$ of IPP / EPC respondents feeling that the current R\&D levels would encourage further investment. The Cramer's V value of 0.61 indicated a large practical significance, and therefore this is an area that should receive attention from the government as it was also believed by $74.2 \%$ of the IPPs and EPCs that they should not be required to provide R\&D funding as part of their tendering conditions, even if this was in place of LCR spend. Furthermore, it was believed that investment in R\&D would not result in more sustainable manufacturing jobs when compared with those LCRs were creating (with $36.4 \%$ of IPP/EPC respondents believing R\&D investment would create sustainable jobs). Having said this, $80 \%$ of the international group felt that investment in $R \& D$ would certainly encourage investment in the sector. To summarise, it could be concluded that LCRs do create jobs and manufacturers are locating in South Africa; however these jobs are not sustainable and R\&D spend together with cluster formation would be a more sustainable path to develop. The responsibility of this development is, however, viewed as being the responsibility of the government and not that of the investors; South Africa should consider this paradigm shift in its industrial policy under the DTI which in turn will influence procurement programmes such as the REIPPPP.

\section{Supply-side constraints}

The market pre-conditions for the effective use of LCRs also infer that there are sufficient local suppliers available to satisfy local demand for products. It was found though by $62.1 \%$ of the IPP/EPC respondents, that there are not enough suppliers to achieve the levels of local content required by the REIPPPP. To further exacerbate the problem of limited suppliers, the goods available locally are not competitively priced (with only $12.1 \%$ of IPPs / EPCs agreeing that there are competitively priced goods available and a Fisher's Exact test value of 0.024 allowed for this statement to be accepted) resulting in IPPs and EPCs being urged to purchase goods at a higher price than they would if they were able to import products. The local suppliers were also unable to produce the goods at the required volume (with only $15.2 \%$ of IPPs /EPCs stating that local suppliers could meet demanded volumes) and - in terms of quality of supply - only $47 \%$ of IPP/EPC respondents believed that local suppliers could deliver the required standard.

The risk of financial penalties and legal action that local manufacturers face in terms of supplying IPP and EPC companies is significant. It was found by $18.2 \%$ of the IPP/ EPC respondents that the local manufacturers were able to absorb this risk. The penalties imposed in the REIPPPP are significant and if the local suppliers are small entities that are newly established, it would be logical to assume that there would be difficulty in ensuring consistency of supply and an inability to afford the penalties should supply obligations not be met. It was also determined that only $40.9 \%$ of the IPP/EPC respondents believed that the local suppliers were BBBEE compliant, which further penalised the IPPs submitting bids. The question regarding a renewable energy manufacturing cluster was asked once again in terms of supplier development and it was strongly suggested (by $80.3 \%$ of IPP/EPC respondents) that this would improve availability of local supply. It could also be inferred that if the clusters had a strong component of BBBEE empowerment, as well as an emphasis on quality, volume and price, it would be more conducive to supporting IPP bids in sourcing local goods.

\section{Summary and conclusion}

This research has been conducted with the view of researcher neutrality towards LCRs as a policy. There are cases where this policy requirement has led to new investment in a particular country and has created jobs, such as those experienced in South Africa; yet in other instances it is very clear that the policy is openly manipulated, possibly due to weaknesses in definition, but also because companies are aiming to provide a project at the best possible price and in order to do this they take advantage of certain loopholes. This may be out of necessity from a shareholder return perspective, but it may also be because they are forced to comply with a policy that is very difficult to do in a market with non-existent enabling pre-conditions.

Without arguing for or against LCRs, it is clear that South Africa has two solutions to embark on within the renewable energy sector, as well as when using national procurement that recommends local content conditions. If South Africa chooses to utilise LCRs going forward, it will have to focus on improved market pre-conditions to ensure that they can 
be successfully implemented without negatively impacting on investment, price of goods and the creation of sustainable jobs. As stated previously, localising a particular good or product may not always be feasible and LCRs should enhance existing manufacturing opportunities as opposed to trying to create opportunities that could not be sustainably supported in the long run. South Africa should also carefully consider the value of the content being localised and the question of higher end value goods being localised, versus cheaper and easier to manufacture goods, must be analysed in greater detail. This would then ensure that longer term and sustainable benefit could be accrued to the economy, and short term, low-value and low-skill components could be avoided.

Should LCRs continue to exist in their current form, dedicated monitoring and action against transgressions must be strengthened as foreign companies that have localised manufacturing are currently being disadvantaged against imported goods. The development of a monitoring and evaluation process should include the public so that a broad consensus is achieved and buy-in for the principle of LCRs can be obtained from all affected citizens. A focus should also be placed on increasing foreign inward investment with technology and skills transfer featuring more strongly in the tendering process.

Developed countries are increasingly avoiding LCRs, as they wish to ensure open and fair global trade and the avoidance of market distortions (bringing unintended repercussions). South Africa should take note of this together with further investment and government support for the development of clusters and R\&D centres, as this would bring in foreign manufacturers, and the country would be competing on a lower cost basis as well as offering new technologies and innovations. This would allow for the market to decide where to invest, instead of being dictated to by policy, and the country would be able to hold a much higher value portion of the renewable energy manufacturing value chain. LCRs could be phased out over time to allow the market to adapt and the cost of renewable energy would most likely come down, allowing South Africa to transition towards a lower carbon energy source.

The primary aim of this research was to analyse how LCRs impact on the South African renewable energy sector. This was achieved by firstly, determining the key drivers that could impact on investment attraction in the South African renewable energy sector. The drivers were identified and during the survey process the key drivers were tested with the simultaneous use of local content policy. The impact, as perceived by the survey respondents, on the renewable energy projects and investment was analysed. Due to certain key drivers not being present in the economy, the impact and effect of LCRs has not been optimal and it has been determined to be an unsustainable mechanism to continue using into the future. The definition of LCRs is more focused on 'spend' rather than 'content' and this has led to a mismatch of the outcomes of the policy versus the original intended objectives. A secondary objective of this research was to investigate the impact of LCRs on the pricing of renewable energy. This was achieved and it is evident that LCRs increase the price of energy, which is passed on to the energy consumer.

It was found that South African renewable energy resources do exist, providing good potential for investment in renewable energy projects, and that the logistics infrastructure was sufficient. The demand created by the REIPPPP provided a sufficiently large market but there was uncertainty in the long term planning and stability, so from a market perspective the stability and clear, predictable planning could be further enhanced. Government had created a sufficient platform for investment but areas of development, such as manufacturing clusters and R\&D and skills training would create a better support environment for LCR policy; and strict monitoring of LCRs would be required to prevent any manipulation. The use of LCRs increases project costs and risk, which is passed on to the energy consumers, but this could be reduced if local goods were more readily available, at the right price and at the right quality and quantity. Focus on manufacturing clusters would once again assist in this regard as IPP and EPC entities would be able to source components and goods locally in a more cost effective manner. As the LCRs currently stand in the REIPPPP it would seem that South Africa is making renewable energy more expensive and although it is argued that this is done for the benefit of creating a new industry and jobs, these are not sustainable and therefore the current LCR policy will only create short term benefits.

In terms of answering how LCRs may impact on the South African renewable energy sector, it could be suggested that there are suboptimal impacts on the welfare of the economy because of missing pre-conditions that would typically allow for the successful implementation of LCR policy. South Africa must consider either strengthening LCR policy through the provision of improved market conditions as well as monitoring and evaluation, or withdrawing them from procurement over a certain time period with a more focused effort being placed on R\&D and innovation, in combination with manufacturing cluster formations. This will allow local manufacturers to compete globally in an open trading field without artificial advantages created by protectionist measures. This will also allow for renewable energy tariffs to be driven downwards, accelerating market acceptance of the energy carrier. The jobs and manufacturing created will be competitive and more sustainable, compared to those created via LCRs.

\section{Acknowledgements Competing interests}

The authors declare that they have no financial or personal relationships which may have inappropriately influenced them in writing this article. 


\section{Authors' contributions}

C.E. did the research for degree purposes. H.L. was the research supervisor and mentor.

\section{References}

Abrahams, F., 2012, 'The key requirements for the establishment of a successful renewable energy manufacturing hub in Atlantis', Research report presented in partial fulfilment of the requirements for the degree of Masters of Business Administration at the University of Stellenbosch, viewed 15 April 2015, from http://scholar.sun.ac.za

Baker, L. \& Wlokas, H., 2014, South Africa's renewable energy procurement: A new frontier, Working paper 159, June 2014, Tyndall Centre for Climate Change Research, Norwich, England.

Barnes, J. \& Black, A., 2013, 'The Motor Industry Development Programme 1995-2012: What have we learned?', International Conference on Manufacturingled Growth for Employment and Equality, May 2013, Johannesburg.

Department of Energy of the Republic of South Africa (DOE), 2011a, Integrated resource plan for electricity 2010-2030, Revision 2, Final report, issued by the DOE on 25 March 2011, South African Department of Energy, Pretoria.

Department of Energy of the Republic of South Africa (DOE), 2011b, Tender No: DOE/001/2011/2012, Request for Qualification and Proposals for New Generation Capacity Under the IPP Procurement Programme.

Department of Energy of the Republic of South Africa (DOE), 2014a, Tender No: DOE/003/13/14, Request for Qualification and Proposals for New Generation Capacity Under the REIPP Procurement Programme, Volume 5: Economic Development Requirements, Updated for the Fourth Bid Submission Date, South African Department of Energy, Pretoria.

Department of Energy of the Republic of South Africa (DOE), 2014b, The future of CSP in the REIPPP Programme, issued by the DOE, South African Department of Energy, Pretoria.

Department of Energy of the Republic of South Africa (DOE), 2015, Expansion and acceleration of the independent power producer procurement programme, Media statement, Ms Tina Joemat-Pettersson, Minister of Energy, issued by the DOE on 16th April 2015, South African Department of Energy, Pretoria.

Department of Energy of the Republic of South Africa (DOE), 2016, Independen power producers procurement programme (IPPPP) - An overview, issued by the DOE on 30th June 2016, South African Department of Energy, Pretoria.

Department of Trade and Industry (DTI), 2015, The wind energy industry localisation roadmap in support of large-scale roll-out in South Africa, Integrated Final Repor January 2015, Department of Trade and Industry, Republic of South Africa, Pretoria.

Eberhard, A., Kolker, J. \& Leigland, J., 2014, 'South Africa's renewable energy IPP procurement program: Success factors and lessons', Public-Private Infrastructure Advisory Facility, Washington, DC, viewed 23 July 2014, from http://www.ppiaf.org
Engineering News Article, 2014a, Martins opens way for coal, cogen IPPs, extends renewables allocation, viewed 24 April 2014, from http://www.engineeringnews. co za/article/martins-opens-way-for-coal-cogen-ipps-extends-renewablesallocation-2014-04-14

Engineering News Article, 2014b, Small-scale IPP developers facing finance challenges, viewed 23 July 2014, from http://www.engineeringnews.co.za/article/smallscale-ipp-developers-facing-finance-challenges-2014-06-20

Engineering News Article, 2015, 'Feeling energised - Former massmart chief sets out South African renewable energy stall', Printed Magazine, 3-9th July 2015.

European Bank for Reconstruction and Development (EBRD Blog), 2012, Local content requirements for renewable energy: An unnecessary evil, viewed 25 February 2014, from http://www.ebrdblog.com/wordpress/2012/11/local-content-requirementsfor-renewable-energy-an-unneccessary-evil/

GIZ, 2013a, REI4P value chain analysis: Final report - Creating local opportunities in the renewable energy value chain: Value chain promotion and a guideline for IPP in ZF Mgcawu District, Northern Cape Province, Pretoria, South Africa, viewed 06 August 2014, from http://www.giz.de

GIZ, 2013b, Lessons for the tendering system for renewable electricity in South Africa from international experience in Brazil, Morocco and Peru, Pretoria, South Africa, viewed 06 August 2014, from http://www.giz.de

Kuntze, J. \& Moerenhout, T., 2013, Local content requirements and the renewable energy industry - A good match, International Centre for Trade and Sustainable Development (ICTSD), Geneva, Switzerland.

Lewis, J.I., 2013, The rise of renewable energy protectionism: Emerging trade conflicts and implications for low carbon development, Georgetown University, Global Environmental Politics, Volume 14, Number 4, November 2013 unedited draft, Washington, DC

Nowicki, L.W., 1997, 'Rules of origin and local content requirements: Protectionism after the Uruguay round', The International Trade Journal XI(3), 349-387.

Rennkamp, B. \& Westin, F.F., 2013, Feito no Brasil? Made in South Africa? - Boosting technological development through local content policies in the wind energy industry, Energy Research Centre, University of Cape Town, Cape Town.

SABS, 2011, 'SATS 1286: 2011 Edition 1: Local goods, services and works Measurement and verification of local content', Pretoria, viewed 28 May 2014, from http://www.dti.gov.za/industrial_development/docs/ip/technical.pdf

South African Photovoltaic Industry Association (SAPVIA), 2014, 'Renewable energy sector attracts foreign investors to Africa', viewed 28 May 2014, from http://www. sapvia.co.za/renewable-energy-sector-attracts-foreign-investors-to-africa/

UNEP, 2011, Towards a green economy: Pathways to sustainable development and poverty eradication - A synthesis for policy makers, viewed 25 February 2014 from http://www.unep.org/greeneconomy

Veloso, F., 2001, Local content requirements and industrial development - Economic analysis and cost modeling of the automotive supply chain, Massachusetts Institute of Technology, Cambridge, MA.

Wu, M. \& Salzman, J., 2014, 'The next generation of trade and environment conflicts: The rise of green industrial policy', Northwestern University Law Review 108(2), 401-474. 